\title{
AOR
}

Selected Papers of \#AolR2020:

The $21^{\text {st }}$ Annual Conference of the

Association of Internet Researchers

Virtual Event / 27-31 October 2020

\section{DISINFORMATION CAMPAIGNS ON TWITTER DURING THE BRAZILIAN 2018 PRESIDENTIAL ELECTION}

\author{
Raquel Recuero \\ Universidade Federal de Pelotas/Universidade Federal do Rio Grande do Sul \\ Felipe Soares \\ Universidade Federal do Rio Grande do Sul \\ Otávio Vinhas \\ Universidade Federal de Pelotas
}

Gabriela Zago

University of Oregon

\section{Introduction}

The 2018 Brazilian presidential election happened amidst several controversies, especially surrounding Jair Bolsonaro, the representative from the Social Liberal Party (PSL). Filling his campaign with far-right views and polemic declarations about minorities and opponents, the candidate defeated the leftist Fernando Haddad from the Worker's Party (PT). Bolsonaro's campaign heavy use of social media was also connected to the spread of disinformation by his supporters (Machado et al., 2018). In this context, our proposal focuses on discussing the results of a two years research that started in 2018 about disinformation in political conversations on Twitter during the 2018 presidential campaign in Brazil. Based on a dataset of over 18 million tweets collected through Social Feed Manager (Prom, 2016) through several keywords, we tried, through multiple approaches, to answer the research question: What are the key characteristics of the disinformation campaigns aimed to influence the Brazilian 2018 election through political conversations on Twitter? To discuss this question, we conducted several studies to compare and analyze the data through content analysis, social network analysis and mixed methods analysis. In this proposal, we seek to present a compilation and a more general systematization of these results. In order to do this, we aligned our discussion Suggested Citation (APA): Recuero, R., Soares, F., Vinhas, O., Zago, G. (2020, October 28-31). Disinformation Campaigns on Twitter during the Brazilian 2018 Presidential Election. Paper presented at AolR 2020: The $21^{\text {th }}$ Annual Conference of the Association of Internet Researchers. Virtual Event : AolR. Retrieved from http://spir.aoir.org. 
with three key aspects of the disinformation campaign: (a) content strategies; (b) legitimation strategies and (c) spread strategies. Our goal is to present a case study and offer some insights about disinformation campaigns in Latin America, which is currently an understudied context. This proposal is connected to the conference theme since disinformation has a strong effect on everyday life and often alienates and isolate people.

\section{Theoretical Background}

The impact of social media on political conversations and democracy has been a topic of interest among researchers all over the world. One of the key concerns underlined by Tucker et al. (2018), for instance, is how social media may be driving political conversations towards polarization, and providing a perfect environment for disinformation to spread, undermining democracies. This concern is especially relevant to young democracies, such as Brazil.

Democracy has always been linked to the quality of the debate and conversations that could lead to political engagement. In modern democracies, this participation is usually mediated by traditional mass media, which allows for communication between candidates and the public (Maia, 2008). Social media has changed this landscape by providing a new space for conversations and social interaction, one with different affordances such as anonymity and asynchronicity (Papacharissi, 2004). The discussion about how social media influenced political engagement seems to have initially been positive, partially because political conversations on these platforms were expected to increase diversity and enrich the political debate (Chadwick, 2009; Stromer-Galley, 2003). However, other studies started to show different results; some studies found that conversations on social media tend to cluster people with the same political views, potentially increasing homophily (Gruzd \& Roy, 2014; Bastos, Mercea \& Baronchelli, 2017; Soares, Recuero \& Zago, 2019). Greater polarization and homophily - rather than diversity of opinion - was found in these conversations. This may ultimately lead to less political engagement, an inferior quality to the political debate, and polarization of conversation.

The spread of disinformation has been studied by several authors and through several perspectives. While some like to call it "fake news" (Falis, 2009), others believe this is part of a broader phenomenon called "information disorder" (Derakhshan \& Wardle, 2017). For Derakhshan \& Wardle (2017) disinformation is based on content created to mislead, and it comprises fabricated information or misleading information, created through framing a fact through a false context, or creating a false connection between two facts.

A disinformation campaign is, roughly, the coordinated spread of disinformation as a means to an end, to influence the public opinion through social media. Disinformation campaigns are strongly connected to political propaganda, sometimes used as tools to promote political views (Bastos \& Mercea, 2019). These campaigns often rely on trolls and botnets (Ong \& Cabañes, 2018), political influencers and activists (Soares, Recuero \& Zago, 2018), hyperpartisan outlets (Marwick \& Lewis, 2017), and other strategies to coordinate and legitimate the spread of biased and manipulated content.

Disinformation campaigns are problematic because they negatively influence conversations in the public sphere by misleading people (Derakhshan \& Wardle, 2017). In Brazil, these campaigns are especially effective because hyperpartisan outlets and 
alternative political pages have been increasing their visibility on social media (Soares, Recuero \& Zago, 2019; Alves \& Albuquerque, 2019). In this context, few studies have attempted to organize the general characteristics of these campaigns, which is our goal in this proposal.

\section{Methods}

For data collection, we used Social Feed Manager (Prom, 2016). Social Feed Manager collected tweets during the presidential campaign (from August to October of 2018). We collected tweets based on the names of the front runner candidates, Haddad $(9,555,023$ tweets) and Bolsonaro (16,479,042 tweets). On these datasets, with over 20 million tweets, we identified and further explored the disinformation that circulated on the conversations. Disinformation was classified based on fact-checking outlets and traditional media and similar pieces of the same misleading or false content were classified under the same category (for example, two tweets containing the same disinformation with different framing). We further analyzed more 2000 pieces of disinformation. We worked with multiple methods focusing on our three categories. For the content and legitimation strategies, we worked with discourse analysis (Fairclough, 2001; Van Leeuwen \& Wodak, 1999) and content analysis (Krippendorf, 2014); for the spread strategies we worked on with social network analysis (Wasserman \& Faust, 1994) and content analysis. For the analysis of these datasets, we anonymized the tweets, keeping the identification only for public figures, such as the political actors.

\section{Results}

Our main results are:

\section{Content Strategies}

We found that the majority of the most successful disinformation campaigns were from the right-wing (which increased in time), associated with hyperpartisan outlets and they rely partially on truthful content rather than entirely fabricated information.

These campaigns often attacked mainstream media using hyperpartisan outlets as alternative real news. These strategies combined may be used to create an environment of mistrust and help the spread of disinformation. We also found that the majority of this type of content focused on the demonization of the Worker's Party and the left, as well as the electoral democratic system. This helped set a polarized context for the conversations, which seemed to be key for disinformation campaigns' success (Soares, Recuero \& Zago, 2019).

\section{Legitimation Strategies}




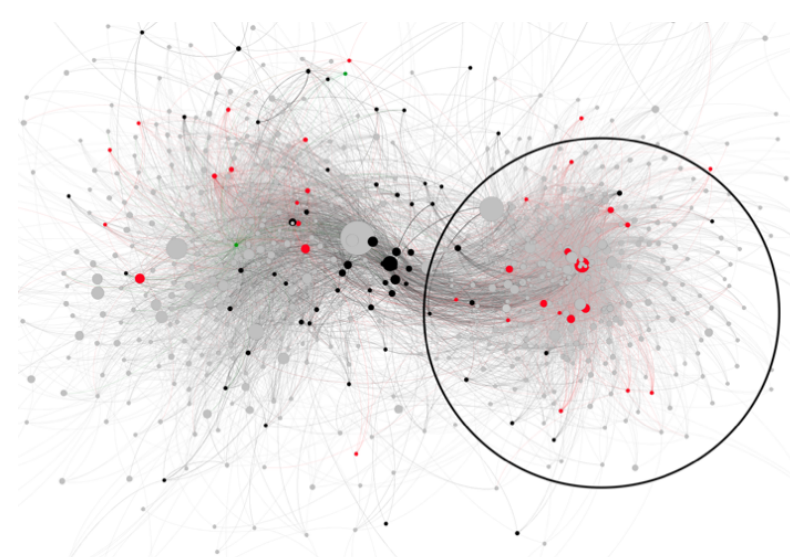

Figure 1 Polarized cluster of conversation about Bolsonaro and Haddad. Bolsonaro's support cluster on the right. Red nodes represent hyperpartisan outlets and black nodes, traditional media outlets.
Disinformation campaigns often used links to hyperpartisan websites and retweets from authorities as to the main source of legitimation. The circulation of content for hyperpartisan outlets is associated with the increase of disinformation within the conversations.

These campaigns also used other strategies, such as framing their stories as a duality between good and evil (mythopoesis, according to Van Leeuwen and Wodak, 1999). These strategies connected to polarization seemed to increase disinformation circulation and decrease traditional news circulation.

\section{Spread Strategies}

The majority of disinformation campaigns i n our case study would to start in small botnets that retweet/mention each other (Recuero \& Gruzd, 2019). They often also mention authorities and other users as a "phishing strategy" to gain visibility. However, it seems that legitimation by the authority was key for virality (Soares, Recuero \& Zago, 2018 and Recuero, Soares \& Zago, 2019). The content was also frequently framed as "urgent" or "bombastic" to encourage users to retweet it. Finally, we found that the polarization and the circulation of hyperpartisan information also plays a key role, isolating clusters around the same political position creating a good environment for disinformation campaigns, as they offered "alternatives" to the "manipulation" of traditional outlets.

\section{References}

Alves, M., Albuquerque, A. (2019). Perda da hegemonia da imprensa: a disputa pela visibilidade na eleição de 2018. Lumina, 13(3), 5-27.

Bastos, M.; Mercea, D. \& Baronchelli, A. 2017. The Spatial Dimension of Online Echo Chambers. [physics.soc-ph]. arXiv:1709.05233v1. Available at: https://arxiv.org/ftp/arxiv/papers/1709/1709.05233.pdf.

Bastos, M. T., Mercea, D. (2019). The Brexit Botnet and User-Generated Hyperpartisan News. Social Science Computer Review, 37(1), 38-54. https://doi.org/10.1177/0894439317734157

Chadwick, A. 2009. 'Web 2.0: New Challenges for the Study of E-Democracy in an Era of Informational Exuberance' I/S: A Journal of Law and Policy for the Information Society 5 (1), pp. 9-41.

Derakhshan, H. Wardle, C. (2017). Information Disorder: Definitions. In Proceedings of Understanding and Addressing the Disinformation Ecosystem. Annemberg: University of Pennsylvania, 5-12. 
Fairclough, N. (2001). Discurso e mudança social. Brasília: Editora UnB.

Gruzd, A. Roy, J. 2014. Investigating Political Polarization on Twitter: A Canadian Perspective. Policy and Internet, 6, 1, 28-45.

Krippendorf, K. 2014. Content Analysis. An Introduction to Its Methodology (3rd ed). California, CA Sage Publications.

Machado, C. Kira, B. Hirsch, G. Marchal, N. Kollanyi, B. Howard, P.. Lederer, T. Barash, V. (2018). News and Political Information Consumption in Brazil: Mapping the First Round of the 2018 Brazilian Presidential Election on Twitter. Data Memo 2018.4. Oxford, UK: Project on Computational Propaganda.

Maia, R. C. M. 2008. Visibilidade midiática e deliberação pública. In: Gomes, W. Maia, R. C. M. Comunicação e democracia: Problemas \& Perspectivas. São Paulo: Paulus, 117162.

Marwick, A. \& Lewis, R. (2017). Media, Manipulation and Disinformation Online. Report available

at: https://datasociety.net/pubs/oh/DataAndSociety_MediaManipulationAndDisinformationO nline.pdf

Ong, J.C., \& Cabanes, J.V. (2018). Architects of Networked Disinformation: Behind the Scenes of Troll Accounts and Fake News Production in the Philippines. doi: 10.7275/2cq4-5396.

Papacharissi, Z. 2004. Democracy online: civility, politeness, and the democratic potential of online political discussion groups. New Media \& Society, 6(2), 259-283. Doi:10.1177/1461444804041444.

Prom, C. (2016). Social Feed Manager. George Washington University Libraries. Zenodo. https://doi.org/10.5281/zenodo.597278.

Recuero, R. \& Gruzd, A. 2019. Cascatas de Fake News Políticas: um estudo de caso no Twitter. Galáxia (São Paulo) n.41, pp.31-47. Epub May 23. Doi: 10.1590/198225542019239035.

Stromer-Galley, J. 2003. Diversity of Political Conversation on the Internet: Users' Perspectives, Journal of Computer-Mediated Communication, Volume 8, Issue 3, 1 April 2003, JCMC836, https://doi.org/10.1111/j.1083-6101.2003.tb00215.x.

Soares, F. B. Recuero, R. \& Zago, G. 2018. Influencers in Polarized Political Networks on Twitter. In Proceedings of the International Conference on Social Media \& Society, Copenhagen, Denmark (SMSociety). doi: 10.1145/3217804.3217909.

Soares, F. B., Recuero, R. Zago, G. 2019. Asymmetric Polarization on Twitter and the 2018 Brazilian Presidential Elections. In Proceedings of the 10th International Conference on Social Media \& Society, Toronto, Canada (SMSociety). doi: 10.1145/3328529.3328546.

Tucker, J. A., Guess, A. Barbera, P. Vaccari, C. Siegel, A. Sanovich, S. Stukal, D. Nyhan, B. 2018. Social Media, Political Polarization, and Political Disinformation: A Review of the Scientific Literature. Available at SSRN: https://ssrn.com/abstract=3144139 or http://dx.doi.org/10.2139/ssrn.3144139. 
Van Leeuwen, T. Wodak, R. (1999). Legitimizing Immigration Control: A DiscourseHistorical Analysis. Discourse Studies, 1(1), 83-118. DOI: 10.1177/1461445699001001005.

Wasserman, S., and Faust, K. 1994. Social Network Analysis. Cambridge: Cambridge University Press. 